\title{
I have only 1 brain but 2 hemispheres: Please perfuse both adequately!
}

\author{
Jean Bachet, MD, FEBCTS
}

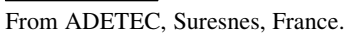

Disclosures: Author has nothing to disclose with regard to commercial support.

Received for publication March 3, 2017; accepted for publication March 10, 2017; available ahead of print April $5,2017$.

Address for reprints: Jean Bachet, MD, FEBTCS, ADETEC, 1, Place Marcel Legras, 92150 Suresnes, France (E-mail: jean.bachet@yahoo.fr).

J Thorac Cardiovasc Surg 2017;154:765-6

$0022-5223 / \$ 36.00$

Copyright (C) 2017 by The American Association for Thoracic Surgery

http://dx.doi.org/10.1016/j.jtcvs.2017.03.032

The article by Tong and colleagues ${ }^{1}$ reports on a rather interesting and rarely addressed topic. The study demonstrated that bilateral perfusion implied less mortality and neurologic morbidity, but the difference did not reach statistical significance. Nevertheless, the authors conclude that bilateral selective cerebral perfusion should be used better in this setting of patients.

Since selective cerebral perfusion was popularized in the late $1980 \mathrm{~s},{ }^{2,3}$ many modifications have been described, but, in all of the initial experiences, bilateral perfusion of the brain was used and not questioned.

Yet, at the end of the 1990s, a major question came out: "Should we perfuse the brain through 1, 2, or even the 3 supra-aortic vessels." 4,5 Since then, the surgical community dealing with aortic arch replacement entered a long dispute resembling a sort of religious debate with strong supporters on each side.

For the group of "bilateralists," the anatomy seems to be in favor of bilateral perfusion. Indeed, the flow to both hemispheres depends on the status of the circle of Willis, and anatomic variations of this structure are common. According to several studies, it has a complete configuration in $42 \%$ to $47 \%$ of subjects, a complete anterior circulation in $74 \%$ of subjects, and a complete posterior circulation in $52 \%$ of subjects, whereas the posterior communicans may be hypoplastic or absent in approximately $25 \%$ to $30 \%$ of subjects, and the anterior communicans may be hypoplastic or absent in approximately $10 \%$ of subjects. ${ }^{6-8}$

Conversely, among "unilateralists," Urbanski and colleagues 9 evaluated the role of completeness of the circle of Willis and found that it was normal in only $60 \%$ of patients. Their conclusion was totally opposed to what was generally admitted. During unilateral perfusion, the flow velocity in the contralateral middle cerebral artery varied considerably, but the flow never ceased. So, they concluded that the anatomic status of the circle of Willis does not correlate with functional and intraoperative cerebral cross-perfusion. ${ }^{9}$

If we look at the clinical results, it appears in the few studies comparing both methods that the rates of mortality

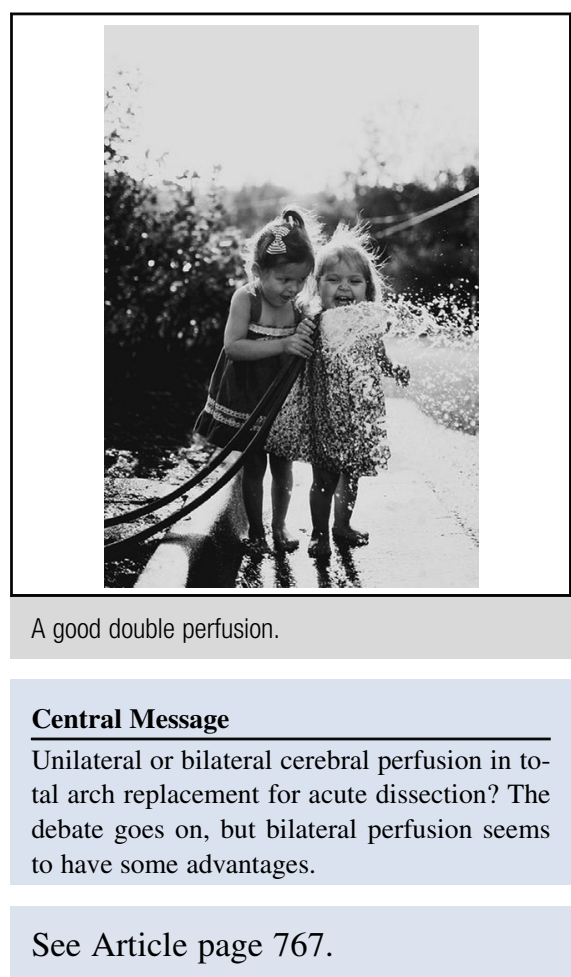

and neurologic disorders are similar. However, one may observe that in most reports, the number of acute dissections is reduced, a large proportion of patients underwent only partial or hemiarch replacements, and the duration of the cerebral perfusion was often inferior to 30 minutes. Conversely, in patients undergoing total arch replacement with a cerebral perfusion time superior to 40 minutes, bilateral perfusion appears to be the technique that is best documented to be safe. ${ }^{10-13}$ This also seems to be the case for the long-term results. ${ }^{14}$

In the present study, bilateral perfusion implied approximately 50\% less mortality and neurologic morbidity rates than unilateral perfusion, but this did not reach statistical significance. The statisticians would say that this is only a trend and no proof, but some trends might be indicative, and significance might be only a matter of number in each arm of the comparison.

Last but not least, let's forget the scientific arguments and turn to simple commonsense-based concepts. When the right axillary, carotid, or innominate artery is cannulated and the cerebral perfusion has been implemented unilaterally, as soon as the arch is opened it takes a few seconds or 1 minute to insert a small balloon cannula into the origin 
of the left carotid artery or in the divided vessel and start bilateral perfusion.

A major question arises: Why should we expose our patients to any undue risk just to avoid a simple maneuver, to spare a little time, or for any other fancy and questionable reason?

This question has been raised for more than 2 decades. We still wait for the answer.

\section{References}

1. Tong G, Zhang B, Zhou X, Tao Y, Yan T, Wang X, et al. Bilateral versus unilateral antegrade cerebral perfusion in total arch replacement for type A aortic dissection. J Thorac Cardiovasc Surg. 2017;154:767-75.

2. Bachet J, Guilmet D, Goudot B, Termignon JL, Teodori G, Dreyfus G, et al. Cold cerebroplegia: a new technique of cerebral protection during operations on the transverse aortic arch. J Thorac Cardiovasc Surg. 1991;102:85-94.

3. Kazui T, Inoue N, Yamada O, Komatsu S. Selective cerebral perfusion during operation for aneurysms of the aortic arch: a reassessment. Ann Thorac Surg. 1992;53:109-14.

4. Reutebuch O, Schurr U, Hellermann J, Prêtre R, Künzli A, Lachat M, et al. Advantages of subclavian artery perfusion for repair of acute type A dissection. Eur J Cardiothorac Surg. 2004;26:592-8.

5. Küçüker SA, Ozatik MA, Saritaş A, Taşdemir O. Arch repair with unilateral antegrade cerebral perfusion. Eur J Cardiothorac Surg. 2005;27:638-43.
6. Macchi C, Catini C, Federico C, Gulisano M, Pacini P, Cecchi F, et al. Magnetic resonance angiographic evaluation of circulus arteriosus cerebri (circle of Willis) (a morphologic study in 100 human healthy subjects). Ital J Anat Embryol. 1996; 101:115-23.

7. Krabbe-Hartkamp MJ, van der Grond J, de Leeuw FE, de Groot JC, Algra A, Hillen B, et al. Circle of Willis (morphologic variation on three-dimensional time-of-flight MR angiograms). Radiology. 1998;207:103-11.

8. Kim GE, Cho YP, Lim SM. The anatomy of the circle of Willis as a predictive factor for intra-operative cerebral ischemia (shunt need) during carotid endarterectomy. Neurol Res. 2002;24:237-40.

9. Urbanski PP, Lenos A, Blume JC, Ziegler V, Griewing B, Schmitt R, et al. Does anatomical completeness of the circle of Willis correlate with sufficient crossperfusion during unilateral cerebral perfusion? Eur J Cardiothorac Surg. 2008; $33: 402-8$.

10. Malvindi PG, Scrascia G, Vitale N. Is unilateral antegrade cerebral perfusion equivalent to bilateral cerebral perfusion for patients undergoing aortic arch surgery? Interact Cardiovasc Thorac Surg. 2008;7:891-7.

11. Lu S, Sun X, Hong T, Yang S, Song K, Lai H, et al. Bilateral versus unilateral antegrade cerebral perfusion in arch reconstruction for aortic dissection. Ann Thorac Surg. 2012;93:1917-20.

12. Preventza O, Simpson KH, Cooley DA, Cornwell L, Bakaeen FG, Omer S, et al. Unilateral versus bilateral cerebral perfusion for acute type a aortic dissection. Ann Thorac Surg. 2015;99:80-7.

13. Olsson C, Thelin S. Antegrade cerebral perfusion with a simplified technique: unilateral versus bilateral perfusion. Ann Thorac Surg. 2006;81:868-74.

14. Krähenbühl ES, Clément M, Reineke D, Czerny M, Stalder M, Aymard T, et al. Antegrade cerebral protection in thoracic aortic surgery lessons from the past decade. Eur J Cardiothorac Surg. 2010;38:46-51. 